Original Research Article

\title{
Evaluation of indoor prescriptions of depression in psychiatry department of a tertiary care hospital in North India
}

\author{
Gurpreet Kaur Randhawa ${ }^{1}$, Navyug Raj Singh ${ }^{1 *}$, Prithwijit Kundu ${ }^{2}$, Swati Prabhakar ${ }^{3}$
}

${ }^{1}$ Department of Pharmacology, Govt. Medical College, Amritsar, Punjab, India ${ }^{2}$ Department of Medical Services, Healthcare Medical advisor, Zuventis Ltd., Mumbai, India

${ }^{3}$ Department of Psychiatry, Intern, Govt. Medical College, Amritsar, Punjab, India

Received: 14 September 2017 Accepted: 03 October 2017

*Correspondence to:

Dr. Navyug Raj Singh,

Email: navyug69@gmail.com

Copyright: (c) the author(s), publisher and licensee Medip Academy. This is an openaccess article distributed under the terms of the Creative Commons Attribution NonCommercial License, which permits unrestricted noncommercial use, distribution, and reproduction in any medium, provided the original work is properly cited.

\begin{abstract}
Background: Depression is one of most common psychiatric illnesses affecting the human population and poses significant economic burden to society. Prescription for depression usually involves multiple medications sometime irrationally prescribed.

Methods: Present study involved evaluation of 65 indoor prescriptions of patients diagnosed with depression from Psychiatry Department in a tertiary care hospital. The prescriptions were evaluated on basis of WHO Core Indicators for writing a good prescription. The demographic characteristics of the patient population were studied. Number of drugs prescribed per prescription and the average number per prescription were calculated to assess polypharmacy. The cost involved in treatment using latest market data from drug information source and the rationality of prescriptions were also evaluated.

Results: $80 \%$ of the prescriptions were not in accordance with the WHO Core Indicators. An average of $2.415 \pm 1.102$ medications were prescribed per prescription indicating polypharmacy. Insignificant difference was observed in cost per prescription per month of medicines when compared with lowest priced products available in market.

Conclusions: Polypharmacy was found in most prescriptions and monotherapy was instituted in five prescriptions only, with clonazepam as the most prescribed antidepressant drug. Majority of prescriptions did not conform to WHO core indicators for prescription writing.
\end{abstract}

Keywords: Prescription analysis, Prescription audit, Polypharmacy, WHO core indicators

\section{INTRODUCTION}

Depression is a significant public health concern across all regions of the world and is strongly related to social conditions. Depression affects a person's ability to work, form and maintain relationships and destroys his/her quality of life. Depressive disorders are currently estimated to affect 350 million people worldwide with approximately 1 in 20 people reporting an episode of depression each year. ${ }^{1}$ Severe depression can lead to a suicidal attempt (responsible for 850000 deaths every year). An estimated $6-12 \%$ of the US population will experience depression at some time. The annual suicide rate is 12.93 per 100,000 individuals. Suicide is the tenth leading cause of mortality. In 2014, the total number of suicide deaths in the United States was $42,773 .^{2}$

Recently conducted world mental health surveys indicate that major depression is experienced by $10-15 \%$ people in their lifetime and about 5\% suffer from major depression in any given year. ${ }^{3,4}$ Lifetime prevalence of all depressive disorders taken together is over $20 \%$ that is one in five individuals. In Indian context, a recent large sample survey with rigorous methodology reported an overall prevalence of $15.9 \%$ for depression, which is similar to western figures. There is some suggestion that perhaps the prevalence of depression has increased over past few 
decades. ${ }^{5,6}$ Studies done in primary health care settings in India have found depression in $21-84 \%$ of the cases. ${ }^{7}$

For the management of depression, there are pharmacological and non-pharmacological options. Pharmacological approach is a primary treatment option for depression as well as for many other anxiety disorders. According to Spence and colleagues, between 1998 and 2012, there was a $165 \%$ increase recorded in the prescribing of antidepressant drugs in England. ${ }^{8}$

Older or first-generation antidepressants have been available for over 50 years with iproniazid being the first drug to be used in the clinical treatment of depression followed by other monoamine oxidase inhibitors (MAOIs) and tricyclic antidepressants (TCAs). ${ }^{9}$ Over the last three decades, second-generation antidepressants, including selective serotonin reuptake inhibitors (SSRIs) and more recently selective serotonin and noradrenaline reuptake inhibitors (SNRIs), have become the frontline pharmacological treatment for depression. ${ }^{10}$ These drugs have comparable efficacy, but lower toxicity in overdose and less troublesome side effects than TCAs and MAOIs. ${ }^{11}$

Considering high incidence of depression, a steep increase in prescription rate, and greater tendency towards polypharmacy, a prescription analysis was envisaged. A short project was undertaken to study the emerging trends in prescriptions for depression and were analysed according to WHO guidelines for writing a good prescription as well as other relevant parameters like average number of drugs per prescription and average treatment cost per month.

\section{METHODS}

Present study was conducted in the Psychiatry Department of a Tertiary Care Hospital in North India. Sixty-five indoor prescriptions (last prescription advised on the bedhead tickets before discharge) with diagnosis of depression were carefully and methodically analysed according to WHO guidelines for writing a good prescription, components (core indicators) of which are: ${ }^{12}$

- Name of prescriber

- Date of prescription

- Name and strength of drug

- Dosage form

- Dosage regimen

- Prescriber's signature or initials

- Name of the patient.

Bed-head tickets with recorded serious co-morbidities like liver disease, renal disease, diabetes, cardiovascular disorders were excluded, so were those with illegible hand writing, soiled or torn pages with incomplete record.

Demographic characteristics of the patient population were assessed. Number of drugs prescribed per prescription and average number of drugs per prescription were calculated to assess polypharmacy. Rationality of prescriptions for depression was also evaluated. The prescriptions in which written diagnosis did not match all the prescribed drugs were considered invalid. Comparative assessment of average actual cost/month/prescription and minimum average cost/month/prescription, using latest market data from drug information source (Drug Update), was also carried out. ${ }^{13}$

\section{RESULTS}

Within the prescription sample $(n=65)$ analysed, 41-60 years of age group was most affected (52.4\%) (Figure 1) with depression with equal prevalence among male $(50.8 \%)$ and female patients $(49.2 \%)$.

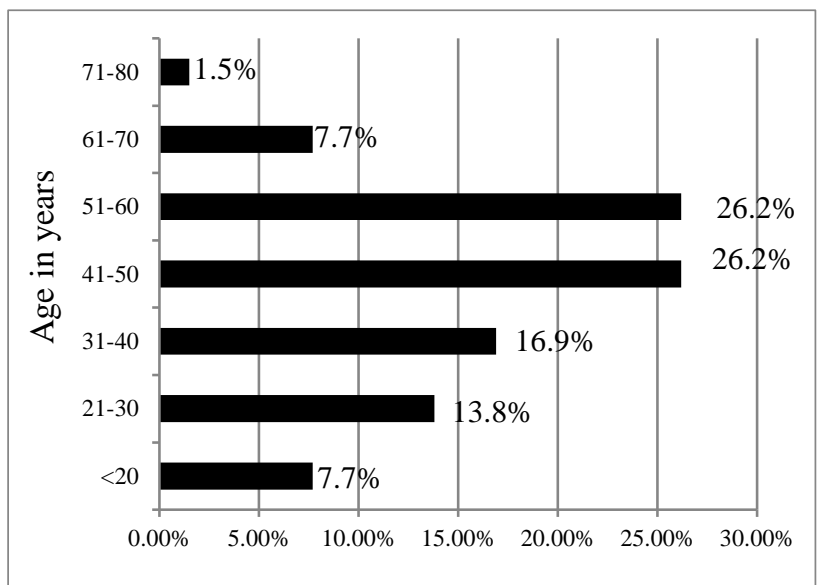

Figure 1: Age-wise distribution of patients of depression.

Overall, $80 \%$ prescriptions didn't conform to WHO Guidelines as per given Core Indicators for writing a good prescription. $50 \%$ prescriptions did not mention the name of the prescriber and his/ her signatures/ initials. Detailed dosage regimen was not written in $50.8 \%$ prescriptions (Table 1).

Table 1: Prescription analysis according to WHO guidelines.

\begin{tabular}{|lll|}
\hline WHO core indicators & $\begin{array}{l}\text { Present } \\
(\%)\end{array}$ & $\begin{array}{l}\text { Absent } \\
(\%)\end{array}$ \\
\hline Name of prescriber & $26(40)$ & $39(60)$ \\
\hline Date of prescription & $65(100)$ & 0 \\
\hline Name and strength of drug & $65(100)$ & 0 \\
\hline Dosage form & $65(100)$ & 0 \\
\hline Dosage regimen & $32(49.2)$ & $33(50.8)$ \\
\hline $\begin{array}{l}\text { Prescriber's signature or } \\
\text { initials }\end{array}$ & $33(50.8)$ & $32(49.2)$ \\
\hline Name of patient & $65(100)$ & 0 \\
\hline
\end{tabular}

Around $78 \%$ of the total drugs prescribed in all 65 prescriptions, were found to conform to the diagnosis of depression. Prescriptions in which written diagnosis did 
not match all the prescribed drugs were considered invalid. Such prescriptions had additional drugs unrelated to depression including antihypertensive, antidiabetics, antihistaminic or multivitamins etc. Diagnosis was missing i.e. not written in 20 prescriptions $(30.76 \%)$. However, all the prescriptions were included in the quantitative analysis of prescribing pattern or in cost analysis.

An average of $2.415 \pm 1.102$ drugs were prescribed per prescription indicating polypharmacy. Monotherapy was instituted in only $5(7.69 \%)$ prescriptions and two drugs were prescribed in $38(58.46 \%)$ prescriptions. Up to five drugs together were prescribed in 21 (32.31\%) prescriptions and $1(1.54 \%)$ prescription contained nine drugs. Most common antidepressant prescribed was escitalopram (50.77\%) followed by duloxetine (29.23\%). Clonazepam $(69.23 \%)$ was the benzodiazepine adjuvant most prescribed along with antidepressants followed by Lorazepam (15.38\%). Antipsychotic agents were also prescribed along with antidepressants as well as sedativehypnotics in some of the prescriptions (Table 2). In one prescription of moderate depressive disorder, clonazepam was prescribed alone and also in combination with escitalopram. In case of monotherapy, escitalopram was the drug most preferred (4 out of total 5) and Mirtazapine was prescribed alone in one instance.

Table 2: Instances of antidepressants and other psychotropic drugs in prescriptions $(\mathrm{n}=65)$.

\begin{tabular}{|c|c|c|c|}
\hline Drug group & & Generic name & Number of prescriptions (\%) \\
\hline \multirow{8}{*}{ Antidepressants } & \multirow{4}{*}{ SSRIs } & Escitalopram & $33(50.77)$ \\
\hline & & Sertraline & $5(7.69)$ \\
\hline & & Paroxetine & $1(1.54)$ \\
\hline & & Fluoxetine & $1(1.54)$ \\
\hline & \multirow{3}{*}{ SNRIs } & Duloxetine & $19(29.23)$ \\
\hline & & Venlafaxine & $1(1.54)$ \\
\hline & & Desvenlafaxine & $1(1.54)$ \\
\hline & NaSSAs & Mirtazapine & $4(6.15)$ \\
\hline \multirow{4}{*}{ Benzodiazepines } & & Clonazepam & $45(69.23)$ \\
\hline & & Lorazepam & $10(15.38)$ \\
\hline & & Zolpidem & $2(3.08)$ \\
\hline & & Chlordiazepoxide & $1(1.54)$ \\
\hline \multirow{4}{*}{ Antipsychotics } & & Risperidone & $2(3.08)$ \\
\hline & & Olanzapine & $1(1.54)$ \\
\hline & & Haloperidol & $1(1.54)$ \\
\hline & & Flupenthixol & $2(3.08)$ \\
\hline
\end{tabular}

Average cost/month/prescription was INR 360 and minimum cost/month/prescription as per the market data was INR 320, with a difference of INR $40 /$ month/prescription which is statistically insignificant (p-value $=0.094)$.

\section{DISCUSSION}

Indoor prescriptions with the diagnosis of depression were included in this study. Depression was found to be most prevalent in middle age groups compared to extreme ages, with almost equal gender-wise distribution. When analysed as per WHO Guidelines, $80 \%$ prescriptions didn't conform to the Core Indicators on the whole. 50\% prescriptions did not mention the name or did not have signatures of the prescriber which is a serious lapse and could lead to various authenticity and accountability issues. A good prescription needs clear and identifiable mention of the prescriber and his/her signatures for authenticity. $50.8 \%$ prescriptions did not have detailed dosage regimen which could lead to ambiguity in dispensing the drugs causing unwarranted treatment failure, non-compliance or toxicity.

More than thirty percent $(32.31 \%)$ of prescriptions reflected polypharmacy having up to five drugs. There were valid and explainable rational combinations in some of the prescriptions but for many no valid reason was mentioned in the record. A number of studies done on psychotropic and antidepressant drugs have shown similar trends of polypharmacy. ${ }^{14,15} 22 \%$ of the drugs prescribed were not valid for the diagnosis of depression. There were additional drugs along with antidepressants which could have been added for various co-morbidities or for minor adverse drug effects or side effects of primary drugs but without recording any such reasons in the bed-head tickets. A rational prescription record demands spelled out reasons for all the drugs prescribed whether co-morbidities, adverse drug effects or any other reasons. 
Escitalopram, an SSRI, was the most commonly prescribed antidepressant followed by duloxetine, an SNRI. Other SSRIs prescribed were sertraline, fluoxetine and paroxetine. Mirtazapine, an atypical antidepressant (also classified as Noradrenergic and Specific Serotonergic Antidepressant) was prescribed to four patients including the one where it was used as monotherapy. Preferred drug for monotherapy was SSRI escitalopram. A study also conducted in North India in 2015 shows a similar predilection for SSRIs but the most prescribed SSRI was fluoxetine followed by escitalopram. Curiously, it also shows benzodiazepines as most coprescribed drugs with antidepressants just like the present study. ${ }^{14}$ Another study conducted recently in South India also shows SSRIs as preferred antidepressants but with escitalopram as most prescribed SSRI. ${ }^{16}$ Interestingly, a large sample $(n=1898)$ study conducted across East Asia in 2007 reports SSRIs as most prescribed antidepressants but paroxetine and fluoxetine top the charts and only a miniscule $(0.2 \%)$ of the patients received escitalopram. ${ }^{17}$ Probably, current trends are tilting in favour of escitalopram compared to other SSRIs. Preferred drug for monotherapy in our study was again escitalopram. Similar preference for escitalopram as a monotherapy was observed in a project conducted in 2016 in Central India. ${ }^{18}$

Adjuvant drugs used along with antidepressants included benzodiazepines viz. clonazepam, lorazepam, chlordiazepoxide and zolpidem. A few patients were also prescribed antipsychotics like risperidone, haloperidol, olanzapine and flunthixol in addition to antidepressants and benzodiazepines.

\section{CONCLUSION}

Proper maintenance of records with rational prescribing is important for a disorder like depression which is undergoing an upswing in modern fast-paced and stressful world order and for which the regimen has to be tailored for optimal response that could be sustained during maintenance phase. Majority of the prescriptions (80\%) included in this study did not conform to the good prescribing practices as outlined in WHO guidelines. Basic indicators like name of prescriber, signatures of prescriber, detailed dosage regimens were missing in many prescriptions.

Many prescriptions had polypharmacy without any valid spelled out reasons and monotherapy was instituted in five prescriptions only. A silver lining was the cost analysis wherein no statistically significant difference between the mean actual cost/month/prescription and mean minimum cost/month/prescription as per market data was seen. Trend towards prescription of SSRIs is reinforced in the present study and most preferred SSRI is escitalopram. SSRIs are followed by SNRIs, duloxetine being the preferred agent. As seen in many other studies, benzodiazepines are most co-prescribed agents along with antidepressants. Limitation of our study was small sample size. Multicentric studies with larger sample size could be carried out to evaluate the latest psychiatrists' preference of prescribing in depression. Recommendation of completeness of prescriptions according to WHO core indicators is desirable.

\section{ACKNOWLEDGEMENTS}

Authors would like to thank Department of Psychiatry, Government Medical College, Amritsar, Punjab, India.

\author{
Funding: No funding sources \\ Conflict of interest: None declared \\ Ethical approval: Not required
}

\section{REFERENCES}

1. Marcus M, Yasamy M, van Ommeren M, Chisholm D, Saxena S. Depression: A Global Health Concern. Available http://www.who.int/mental_health/management/depr ession/who_paper_depression_wfmh_2012.pdf. [accessed on 15.05.2017].

2. USA suicide: 2014 - official final data. Available at https://dphhs.mt.gov/Portals/85/amdd/documents/Pro fessional\%20Persons/2014USSuicideData.pdf. [accessed on 16.05.2017].

3. Bromet E, Andrade LH, Hwang I, Sampson NA, Alonso J, de Girolamo G, et al. Cross-national epidemiology of DSM-IV major depressive episode. BMC Med. 2011;9:90.

4. Murphy JM, Laird NM, Monson RR, Sobel AM, Leighton AH. A 40-year perspective on the prevalence of depression: the Stirling County Study. Arch Gen Psychiatry. 2000;57:209-15.

5. Poongothai S, Pradeepa R, Ganesan A, Mohan V. Prevalence of depression in a large urban South Indian population - The Chennai Urban Rural Epidemiology Study (CURES-70). PloS One. 2009;4:E7185.

6. Nandi DN, Banerjee G, Mukherjee SP, Ghosh A, Nandi PS, Nandi S. Psychiatric morbidity of a rural Indian community changes over a 20 -year interval. $\mathrm{Br}$ J Psychiatry. 2000;176:351-6.

7. Pothen M, Kuruvilla A, Philip K, Joseph A, Jacob KS. Common mental disorders among primary care attenders in Vellore, South India: Nature, prevalence and risk factors. Int J Soc Psychiatry. 2003;49:119-25.

8. Spence R, Roberts A, Ariti C, Bardsley M. Focus on: Antidepressant Prescribing. Trends in the prescribing of antidepressants in primary care. The Health Foundation, Nuffield Trust 2014. Available at http://eprints.mdx.ac.uk/16512/.

9. Lieberman J. History of the use of antidepressants in primary care. Primary care companion. J Clin Psychiatry. 2003;5:6-10.

10. Gartlehner G, Hansen RA, Morgan LC, Thaler K, Lux L, Noord MV, et al. Second-generation antidepressants in the pharmacologic treatment of adult depression. An update of the 2007 comparative effectiveness review. Comparative Effectiveness Reviews No. 46; 2011. Available at http://www.diva- 
portal.org/smash/record.jsf?pid=diva2\%3A810275\& dswid=3098.

11. Bitter I, Filipovits D, Czobor P. Adverse reactions to duloxetine in depression. Expert Opin Drug Saf. 2011:10;839-50.

12. Guide to Good Prescribing, WHO Action Programme on Essential Drugs Geneva.1994. Available at http://apps.who.int/medicinedocs/pdf/whozip23e/who zip23e.pdf.

13. Central Nervous System. In: Arora V, eds. Drug Update: Sri Ganganagar. 2017:340-446.

14. Dutta S, Kaul V, Beg MA, Sindhu S, Singh NK, Dutta $\mathrm{S}$, et al. A psychotropic drug use study among depression patients attending private psychiatric practitioners of Dehradun, Uttarakhand. Int J Med Sci Public Health. 2015;4:634-8.

15. Swamy MK, Wagle L, Giri V. Drug utilization pattern of psychotropic drugs in psychiatric outpatient department of rural tertiary care teaching hospital. Int J Pharm Sci Res. 2016;7(8):3497-08.

16. Kavitha VD, Bhandari PR. First prescription analysis study of depression in a tertiary hospital. World J Pharm Sci. 2017;5(1):49-53.
17. Uchida N, Chong MY, Tan CH, Nagai H, Tanaka M, Lee MS, et al. International study on antidepressant prescription pattern at 20 teaching hospitals and major psychiatric institutions in East Asia: Analysis of 1898 cases from China, Japan, Korea, Singapore and Taiwan. Psychiatry Clin Neurosci. 2007;61(5):522-8.

18. Chattar KB, Karve AV, Subramanyam A, Tondare SB. Prescription pattern analysis of antidepressants in psychiatric outpatient department of tertiary care hospital in India. Asian $\mathbf{J}$ Pharm Clin Res. 2016;9(4):77-9.

Cite this article as: Randhawa GK, Singh NR, Kundu P, Prabhakar S. Evaluation of indoor prescriptions of depression in psychiatry department of a tertiary care hospital in North India. Int J Basic Clin Pharmacol 2017;6:2718-22. 